\title{
How immigrants adapt their smoking behaviour: comparative analysis among Turkish immigrants in Germany and the Netherlands
}

\author{
Katharina Reiss ${ }^{*}$, Odile Sauzet, Jürgen Breckenkamp, Jacob Spallek and Oliver Razum
}

\begin{abstract}
Background: Smoking behaviour among immigrants is assumed to converge to that of the host country's majority population with increasing duration of stay. We compared smoking prevalence among Turkish immigrants residing in two different countries (Germany (DE)/the Netherlands (NL)) between and within countries by time spent in Turkey and DE/NL.
\end{abstract}

Methods: The German 2009 micro-census and the Dutch POLS database (national survey, 1997-2004) were analysed. An interaction variable with dichotomised length of stay (LOS) in Turkey (age: $0-17 ; 18+$ ) and categorised LOS in the host country (immigration year: 1979 and earlier, 1980-1999, 2000-2009; the latter only for Germany) was generated. Age standardised smoking prevalences and sex-specific logistic regression models were calculated.

Results: 6,517 Turkish participants were identified in Germany, 2,106 in the Netherlands. Age-standardised smoking prevalences were higher among Turkish immigrants in the Netherlands compared to those in Germany: $62.3 \%$ vs. 53.1\% (men/lower education); 30.6\% vs. 23.0\% (women/lower education). A similar trend was observed for the majority population of both countries. The chance of being a smoker was lower among Turkish men with short LOS in Turkey and middle LOS in Germany/the Netherlands compared to those with short LOS in Turkey and long LOS in Germany/the Netherlands ( $\mathrm{NL}: \mathrm{OR}=0.57[95 \% \mathrm{Cl}=0.36-0.89]$; $\mathrm{DE}: \mathrm{OR}=0.73[95 \% \mathrm{Cl}=0.56-0.95]$ ). Contrary to that, the chance of being a smoker was higher among Turkish men with long LOS in Turkey and middle LOS in Germany/the Netherlands compared to those with long LOS in Turkey and long LOS in Germany/the Netherlands (NL: OR $=1.35[95 \% \mathrm{Cl}=0.79-2.33$ ]; $\mathrm{DE}: \mathrm{OR}=1.44[95 \% \mathrm{Cl}=1.03-2.02]$ ). The effects for Turkish women were similar, but smaller and often non-significant.

Conclusion: Turkish immigrants adapt their smoking behaviour towards that of the Dutch/German majority population with increasing duration of stay. This was particularly obvious among those who left Turkey before the age of 18 years a group that needs tailored interventions to prevent further increases in smoking. Those who left Turkey as adults and spent a short time in the host countries show 'imported' smoking patterns. A limitation of this study is the use of cross-sectional data: a cohort effect cannot be ruled out. Our findings have to be confirmed with longitudinal data.

Keywords: Smoking, Emigrants and immigrants, Comparative study, Netherlands, Germany, Length of stay

\section{Introduction}

Smoking is one of the leading causes for various cancers (e.g. lung, oral, pancreas or stomach cancer) and cardiovascular diseases (e.g. atherosclerosis or myocardial infarction) [1-3]. It is known to be strongly associated with the socioeconomic position at the individual level but may also be influenced by political tobacco control

\footnotetext{
*Correspondence: katharina.reiss@uni-bielefeld.de

Department of Epidemiology \& International Public Health, Bielefeld School of Public Health (BiSPH), Bielefeld University, P.O. Box 1001 31, 33501 Bielefeld, Germany
}

efforts at the macro level $[4,5]$. While smoking behaviour in general is well studied, research is scarce in terms of smoking among persons with a personal immigration experience. Here, the question arises of whether and how immigrants adapt to the smoking behaviour of the majority population of a country.

In 2011, $1.8 \%(\mathrm{n}=1,491,000)$ of the population of Germany and $1.2 \%(\mathrm{n}=197,042)$ of the population of the Netherlands were born in Turkey [6,7]. Given the special situation of a population that emigrated from the same country of origin and resides in two different host 
countries, a comparison of the smoking behaviour between Turkish immigrants now residing in Germany and the Netherlands would reveal a possible societal influence of the different host countries. As current smoking might also be influenced by the society of the country of origin, it is important to take this aspect into account as well.

The aim of our study is (I) to compare the smoking behaviour among Turkish immigrants between Germany and the Netherlands and (II) to analyse the smoking behaviour among Turkish immigrants within Germany and the Netherlands by duration of stay in Turkey as well as in the respective host country (see Figure 1). We use German and Dutch survey data and calculate standardised smoking prevalences as well as sex-specific logistic regression models. Both between-country and within-country comparisons are required to detect a possible adaptation in smoking behaviour among Turkish immigrants.

\section{Background}

Both Germany and the Netherlands recruited "guest workers" from Turkey following recruitment agreements in 1961 and 1964, respectively. The work-related migration from Turks with a lower socioeconomic status had its peak in the late 1960s and early 1970s. After the oil crisis in 1973 the recruitment stopped, but family reunification continued until the late 1970s. In 1980, political conditions in Turkey resulted in a second immigration wave to Western Europe, this time of refugees and asylum seekers with a higher socioeconomic status $[8,9]$.

In 1993, 58\% of Turkish men and 14\% of Turkish women were smokers [10]. By 2011, this had declined to $42 \%$ among men and $13 \%$ among women. In middleand low-income countries a decreasing trend can be observed among men; smoking prevalences among women, however, are still very low and remained stable over time. In high-income countries there is also a decreasing trend in smoking behaviour among men but still a slightly increasing trend among women. In Germany, $35 \%$ of the men and $25 \%$ of the women reported smoking in 2011, compared to 29\% (men) and 23\% (women) in the Netherlands [11].

In Turkey, unlike in Germany and the Netherlands, women still experience a strong social pressure against smoking. Moreover, whereas smoking is strongly linked to a lower educational level in Germany and the Netherlands, this is only observed among men but not among women in Turkey. Turkish women with a higher educational level are more likely to smoke than those with a lower educational level $[10,12,13]$. Turkey banned smoking in public places in 1996 while the Netherlands did so already in 1990. In Germany it was not until 2007 that a smoke-free legislation was enforced for federal facilities and public transport; however, smoking in bars and restaurants, for example, is regulated by the individual states ("Länder") of Germany $[10,14,15]$.

In Germany and the Netherlands only a few studies have dealt with smoking behaviour among migrants in general and Turkish migrants in particular. In Germany, smoking prevalence among Turkish immigrants converged to that of the autochthonous population with increasing duration of stay; within the Turkish population more men than women smoked and prevalences were higher among men with lower educational level compared to those with a higher level, whereas the opposite applied to women $[16,17]$. Similarly, in the Netherlands, the smoking prevalence was higher among Turkish men than among Turkish women, with similar differences by educational level as those observed in Germany [18-21]. These socioeconomic differences are, however, not universal and depend on the immigrant group under study and the smoking patterns the group experienced in their countries of origin and host countries [22].

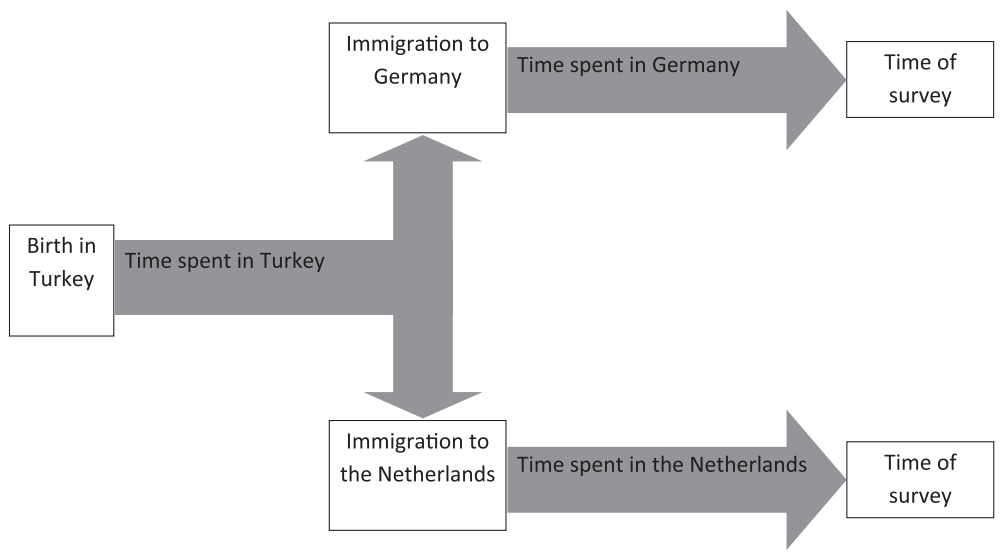

Figure 1 Course of immigration among persons from Turkey now residing in Germany and the Netherlands. 
According to Schooling \& Kuh [23], not only the individual and social perceptive but also a temporal perspective needs to be taken into account when analysing smoking behaviour. Migrants may virtually 'import' health risks and resources from their countries of origin which, in turn, may be prone to change with increasing duration of stay in the host country [24]. The changing health behaviour in the host country might be the result of an acculturation process which starts immediately after arrival in the host country [25]. Acculturation describes a complex and dynamic process through which attitudes and behaviours of people change in consequence of interactions with individuals in their new social environment [26]. The concept of acculturation is widely used in health behaviour research where it is quantified using different measures that range from indirect proxy measures (such as length of stay and proficiency in the language of the host country) to multidimensional scales [27-30]. Studies on the association between acculturation and smoking among immigrants to the US show that prevalences are very low among recent immigrants from economically less developed countries now residing in developed countries but seem to increase with duration of stay in the host country [31-38].

However, the smoking behaviour does not only depend on the time spent in the host country but also on the time spent in the country of origin [39]. For immigrants this means that current smoking patterns might be influenced by the perceived social acceptance of smoking in the country of origin as well as the adaptation towards the smoking patterns in the host country with increasing duration of stay [40]. The host country's political efforts concerning immigration and integration may also influence a possible adaptation [41].

\section{Methods}

\section{Data sources}

Dutch and German survey data was analysed. For the Netherlands, the POLS-basic data was used. POLS (Dutch: Permanent OnderzoekLeefSituatie) is an annual survey of the living situation among Dutch households. Computer-assisted personal or telephone interviews are used as standard questioning techniques. POLS-basic started in 1997 . The annual response rate ranged between 53\% (1998) and 66\% (2006). The number of participants decreased steadily between $1997(34,439)$ and $2009(9,118)[42,43]$. As the annual number of migrants from Turkey with an average of approx. 250/year was too small to obtain stable results, eight years (1997$2004^{\mathrm{a}}$ ) were combined. There was no overlapping in the data as people were not surveyed repeatedly. Yearspecific descriptive analyses revealed no divergent results compared to the combined analysis.
In Germany, the 2009 micro-census (German: Mikrozensus) was used. The micro-census is a survey conducted annually on a sample of $1 \%$ of all households (approx. 390,000 households and 830,000 individuals). Computer-assisted personal interviews are used as standard questioning technique. As with the POLS survey, there were no bilingual interviewers and translated instruments. Participating in the micro-census is obligatory. The survey consists of an annual basic programme and an additional programme which is included every four years. The latter contains additional information on health (answer voluntary) and migration (answer obligatory) among others [44]. For this study, the scientific use file of the 2009 micro-census was utilised. It is a randomly drawn $70 \%$ sub-sample of the original file including data on 489,349 individuals.

\section{Variables used for analyses}

In the Netherlands, Turkish immigrants were identified via country of birth (Turkey). In Germany, because no information on country of birth was available, citizenship was used as the main indicator for immigrant background. Persons from Turkey were identified by means of the following: birth in Germany (no) and citizenship (only Turkish : German and Turkish (dual citizenship): only German with preceding naturalisation and Turkish citizenship before naturalisation). Lengths of stay (Turkey, Germany/the Netherlands) were determined via year of birth, year of immigration and year of survey. In both countries smokers were identified based on the question "Do you smoke?". Those answering "yes" in the Netherlands (only one category in the original dataset) and "yes, regularly" or "yes, occasionally" in Germany (two categories in the original dataset) were considered smokers in our study.

According to the study aim, a temporal interaction variable with dichotomised length of stay (LOS) in Turkey and categorised LOS in the respective host country was generated for the final analyses. LOS in Turkey was dichotomised in the following way: 0-17 years, 18 years and longer. LOS in the host countries was categorised in three categories according to the immigration waves of Turks to both countries: 1979 and earlier, 1980-1999 and 2000-2009 (recent immigrants). For the Dutch data, the first two categories were generated (1979 and earlier, 1980 and later) as the number of Turkish immigrants was too small between 2000 and $2004(n=26)$.

Information on sex, age (in years), education, occupation and income were present in both datasets. In Germany, the International Standard Classification of Education (ISCED) was available, whereas in the Netherlands education was only available in countryspecific categories. As these measures serve as background 
information and are not directly linked to the study aim, partial inconsistency was accepted.

\section{Statistical analyses}

This study investigates the smoking prevalence of a population that emigrated from the same country of origin to two different host countries. The question is whether there are differences in smoking behaviour among Turkish immigrants between Germany and the Netherlands. We calculated age standardised smoking prevalences and 95\% confidence intervals for Turkish immigrants of both countries by sex and binary educational level. We applied the direct age standardisation method by weighting the age-specific smoking prevalences of the Turkish immigrants with the population share in the respective age groups of the old European Standard Population. For comparison, we also calculated age standardised smoking prevalences for the nonTurkish population of Germany and the Netherlands. We also investigated whether the LOS in Turkey as well as in Germany or the Netherlands has an effect on the smoking status of Turkish immigrants. We conducted logistic regression models with smoking as binary dependent variable and the temporal interaction variable as independent variable. We have, in a previous step, also estimated the single effects of LOS in Turkey and LOS in Germany/the Netherlands. Moreover, we have calculated logistic regression models with LOS as continuous variables but because the patterns observed were similar for both regression models, we decided to present the results of the models with the categorical LOS variables in order to facilitate an easier interpretation of the results. To control for confounders, socioeconomic variables (education, occupation, income) and age (for the Dutch data also survey year) were included in the models. The study population in both countries was restricted to persons aged 18-64 years due to the limited number of adolescents and older persons. Models were calculated separately for men and women. All analyses were performed using Stata Version 12.

\section{Results}

In the German micro-census 6,517 participants aged 18-64 years were identified as Turkish immigrants. In the Netherlands, a total of 2,106 persons from Turkey aged 18-64 years participated in the POLS surveys. For characteristics of the study populations in both countries see Table 1.

\section{Between-country comparison}

The crude smoking prevalence among Turkish immigrants in the Netherlands was $47.1 \%$ in total, $33.6 \%$ for women and $58.9 \%$ for men. In Germany, the crude prevalences were $38.3 \%, 25.3 \%$ and $51.2 \%$ respectively. Age standardised prevalences among Turkish immigrants were $44.3 \%$ (total), $29.4 \%$ (women) and $56.6 \%$ (men) for the Netherlands and $37.2 \%$ (total), 23.9\% (women) and $50.7 \%$ (men) for Germany. Both the overall smoking prevalence and that among women and men were higher among Turkish immigrants in the Netherlands compared to those in Germany.

The same trend became apparent when additionally stratifying the results by educational level (see Figure 2). The age standardised smoking prevalence was significantly higher among Turkish men and women with lower educational level in the Netherlands compared to their counterparts in Germany (men: $62.3 \%$ vs. 53.1\%; women: $30.6 \%$ vs. $23.0 \%$ ). The following pattern, in turn, was similar between Turkish immigrants in Germany and the Netherlands: there were indications of a higher smoking prevalence among less educated men compared to more educated men but a lower prevalence among less educated women compared to more educated women. Moreover, smoking prevalence was significantly higher among men than among women in both countries (not significant among higher educated persons in the Netherlands). Concerning the age standardised smoking prevalence among the non-Turkish population there were also indications of a higher smoking prevalence among persons from the Netherlands compared to their counterparts from Germany (e.g. women with low education: $42.7 \%$ vs. $36.6 \%$; exception: men with higher education) (see Figure 2).

\section{Within-country comparison}

The multiple logistic regression models, adjusted for education, occupation, income and age (also survey year in the Dutch data) showed differences in smoking behaviour among Turkish immigrants depending on LOS in country of origin and host country: the chance of being a smoker was lower among Turkish men with short LOS in Turkey (TR) and middle LOS in Germany (DE)/the Netherlands (NL) compared to those with short LOS in Turkey and long LOS in Germany/the Netherlands (NL: $\mathrm{OR}=0.57 \quad[95 \% \mathrm{CI}=0.36-0.89] ; \quad \mathrm{DE}: \quad \mathrm{OR}=0.73$ $[95 \% \mathrm{CI}=0.56-0.95])$. Contrary to that, the chance of being a smoker was higher among Turkish men with long LOS in Turkey and middle LOS in Germany/the Netherlands compared to those with long LOS in Turkey and long LOS in Germany/the Netherlands (NL: $\mathrm{OR}=1.35$ [95\% CI $=0.79-2.33] ; \mathrm{DE}: \mathrm{OR}=1.44 \quad[95 \% \mathrm{CI}=$ 1.03-2.02]). A similar pattern was observed for Turkish women in both countries: the chance of being a smoker was also lower among those with short LOS in Turkey and middle LOS in Germany/the Netherlands compared to those with short LOS in Turkey and long LOS in Germany/the Netherlands (NL: OR $=0.62$ [95\% CI $=0.40-0.97]$; DE: $\mathrm{OR}=0.81[95 \% \mathrm{CI}=0.59-1.10])$. Compared to Turkish 
Table 1 Characteristics of the study population (18-64 years) in the Netherlands and Germany

\begin{tabular}{|c|c|c|c|c|c|c|}
\hline \multirow[b]{2}{*}{ Variable } & \multicolumn{3}{|c|}{ The Netherlands (1997-2004) } & \multicolumn{3}{|l|}{ Germany (2009) } \\
\hline & Item & $\mathrm{n}$ & $\%$ & Item & $\mathrm{n}$ & $\%$ \\
\hline \multirow[t]{5}{*}{ Age (in years) } & $18-29$ & 675 & 32.05 & $18-29$ & 853 & 13.09 \\
\hline & $30-44$ & 998 & 47.39 & $30-44$ & 3179 & 48.78 \\
\hline & $45-64$ & 433 & 20.56 & $45-64$ & 485 & 38.13 \\
\hline & Total & 2106 & 100.00 & Total & 6517 & 100.00 \\
\hline & \multicolumn{4}{|c|}{ Mean: 35.86 (SD: 10.73) } & \multicolumn{2}{|c|}{ Mean: 42.00 (SD: 11.00} \\
\hline \multirow[t]{3}{*}{ Sex } & Men & 1122 & 53.28 & Men & 3287 & 50.44 \\
\hline & Women & 984 & 46.72 & Women & 3230 & 49.56 \\
\hline & Total & 2106 & 100.00 & Total & 6517 & 100.00 \\
\hline \multirow[t]{6}{*}{ Immigration year to host country $^{1}$} & & & & $2000-2009$ & 728 & 11.17 \\
\hline & 1980 and later & 1081 & 51.33 & 1980-1999 & 2993 & 45.93 \\
\hline & 1979 and earlier & 986 & 46.82 & 1979 and earlier & 2556 & 39.22 \\
\hline & Missing & 39 & 1.85 & Missing & 240 & 3.68 \\
\hline & Total & 2106 & 100.00 & Total & 6517 & 100.00 \\
\hline & \multicolumn{3}{|c|}{ Mean length of stay: 18.25 (SD: 8.34) } & \multicolumn{3}{|c|}{ Mean length of stay: 24.30 (SD: 10.94) } \\
\hline \multirow[t]{5}{*}{ Length of stay in Turkey (in years) } & $0-17$ & 1006 & 47.77 & $0-17$ & 2822 & 43.30 \\
\hline & 18 and longer & 1061 & 50.38 & 18 and longer & 3455 & 53.02 \\
\hline & Missing & 39 & 1.85 & Missing & 240 & 3.68 \\
\hline & Total & 2106 & 100.00 & Total & 6517 & 100.00 \\
\hline & \multicolumn{3}{|c|}{ Mean: 17.62 (SD: 9.27) } & \multicolumn{3}{|c|}{ Mean: 18.14 (SD: 9.25) } \\
\hline \multirow[t]{6}{*}{ Education $^{2}$} & & & & ISCED 1 (low) & 2188 & 33.57 \\
\hline & & & & ISCED 2 (low) & 2256 & 34.62 \\
\hline & Low & 1197 & 56.84 & ISCED 3/4 (high) & 1703 & 26.13 \\
\hline & High & 587 & 27.87 & ISCED 5/6 (high) & 342 & 5.25 \\
\hline & Not coded ${ }^{3}$ or missing & 322 & 15.29 & Missing & 28 & 0.43 \\
\hline & Total & 2106 & 100.00 & Total & 6517 & 100.00 \\
\hline \multirow[t]{3}{*}{ Occupation } & Existent & 1043 & 49.53 & Existent & 3457 & 53.05 \\
\hline & Non-existent & 1063 & 50.47 & Non-existent & 3060 & 46.95 \\
\hline & Total & 2106 & 100.00 & Total & 6517 & 100.00 \\
\hline \multirow[t]{6}{*}{ Net income per month ${ }^{4}$} & & & & Low (<900€) & 2115 & 32.45 \\
\hline & & & & Middle (900€ until <2000€) & 2063 & 31.66 \\
\hline & Existent & 1298 & 61.63 & High $(2000 €+)$ & 730 & 11.20 \\
\hline & Non-existent & 350 & 16.62 & Non-existent & 1198 & 18.38 \\
\hline & Not coded ${ }^{3}$ or missing & 458 & 21.75 & Missing & 411 & 6.31 \\
\hline & Total & 2106 & 100.00 & Total & 6517 & 100.00 \\
\hline
\end{tabular}

${ }^{1}$ Only two categories for the Dutch data as number of cases between 2000 and 2004 was only $n=26$.

${ }^{2}$ Country-specific classification of education in the Netherlands ('low' means only compulsory education) compared to the International Standard Classification of Education (ISCED) in Germany; ISCED levels $1+2$ are referred to as 'low education', levels 3 to 6 are referred to as 'high education'.

${ }^{3}$ In the Dutch survey from 1998 some information were not coded in the dataset for the stated number of participants in the table; missing information could not be retrieved.

${ }^{4}$ Income refers to all possible sources of income, not only to salary.

women with long LOS in Turkey and long LOS in Germany/the Netherlands, the chance of being a smoker was higher among those with long LOS in Turkey and middle LOS in Germany (OR $=1.19$ [95\% CI $=0.82-1.74]$ ) but lower among their counterparts in the Netherlands
$(\mathrm{OR}=0.91[95 \% \mathrm{CI}=0.49-1.71)$ (see Table 2). In general, the effects for Turkish women with long LOS in Turkey were not significant and also small in both countries.

The comparison of the age standardised smoking prevalences within Germany and the Netherlands revealed 

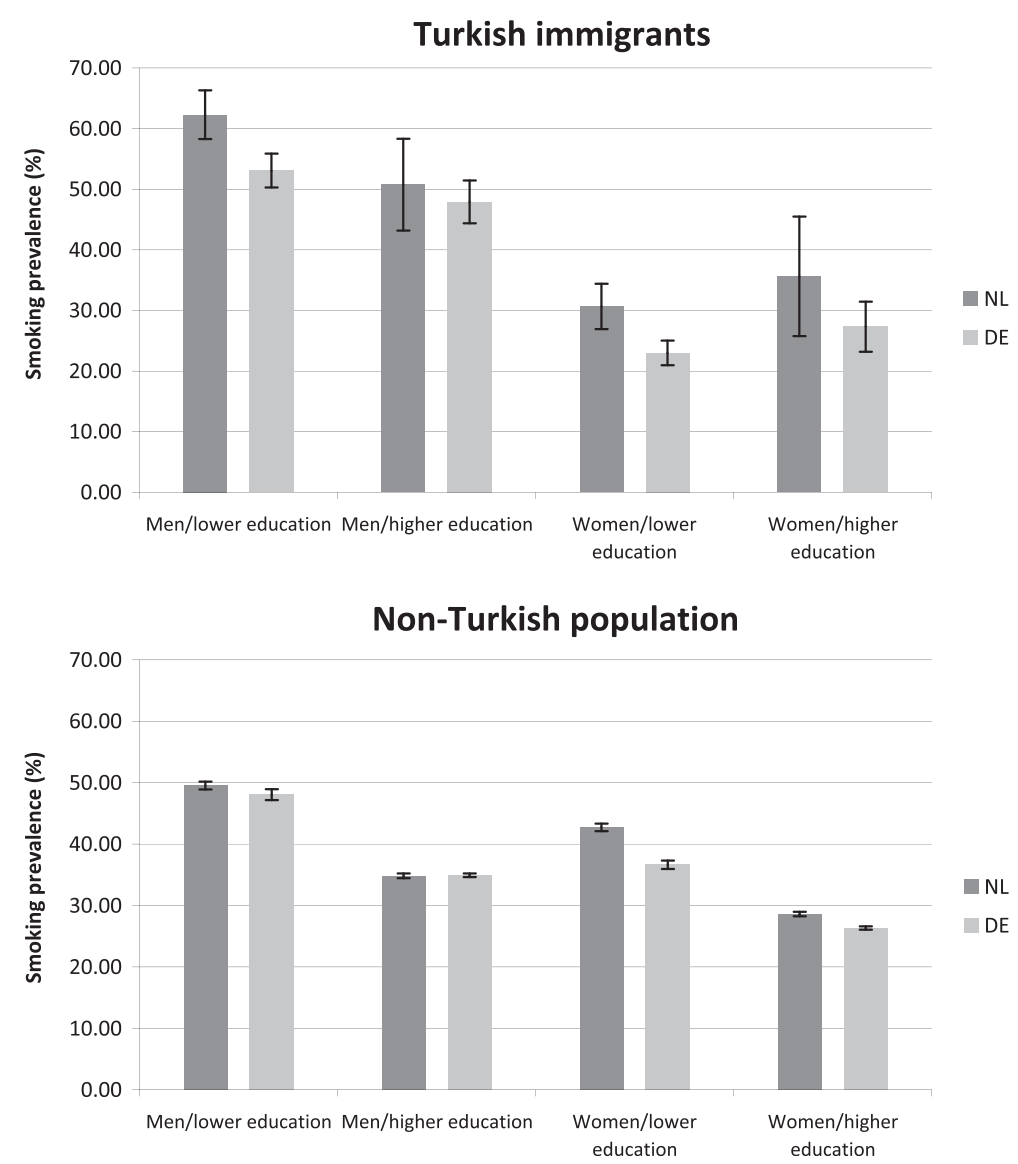

Figure 2 Comparison of age standardised smoking prevalences (in\%) between Turkish participants in Germany (DE) and the Netherlands (NL)/Non-Turkish participants in Germany and the Netherlands (between-country-comparison).

significantly higher prevalences among Turkish men than among non-Turkish men (see Figure 3). Prevalences among women with higher education indicated a similar pattern, but the difference was not significant. Among women with lower education the contrary became apparent: non-Turkish women had a significantly higher smoking prevalence than Turkish women. These patterns apply both to Germany and the Netherlands.

\section{Discussion}

The most important findings of this study were that (I) the smoking prevalence among Turkish immigrants living in the Netherlands is higher than among their counterparts in Germany (irrespective of sex, age and educational level) and that (II) clear differences in smoking behaviour depending on LOS in Turkey and LOS in the respective host country were observed both within Germany and the Netherlands.

A possible reason for the higher smoking prevalence among Turkish immigrants living in the Netherlands compared to those living in Germany can be found in the prevalence among the non-Turkish population.
Contrary to the estimates from the WHO [11], our analysis indicates a higher smoking prevalence among the majority population of the Netherlands compared to that of Germany. This might be partly due to differences in data sources, survey periods and questioning techniques. However, the differences in patterns between the two countries that we observed are reflected by the respective lung cancer rates, which are indicative of past smoking behaviour. Age standardised incidence (1990-2002) and mortality (1990-2010) rates for lung cancer are again higher among the Dutch than among the German population for both men and women [45]. It seems that Turkish immigrants adapted to the (different) smoking behaviours of the majority population of their respective host country. Such an adaptation might explain the observed differences in smoking behaviour among a population that actually emigrated from the same country of origin to two countries with a different smoking behaviour. However, immigrants are not only influenced by the majority population of the host country but might also themselves influence the majority population's health behaviour [46]. Acculturation is an interactive 
Table 2 Binary logistic regression models for smoking among Turkish immigrants (men and women) in the Netherlands and Germany by length of stay in the country of origin and the respective host country (TR $=$ Turkey, NL $=$ the Netherlands, DE $=$ Germany $)^{1,2,3}$

\begin{tabular}{|c|c|c|c|c|c|c|}
\hline \multicolumn{7}{|l|}{ THE NETHERLANDS } \\
\hline \multirow[b]{2}{*}{ Interaction variable (length of stay in TR and NL) } & \multicolumn{3}{|c|}{ Men (number of observations $=\mathbf{8 5 2}$ ) } & \multicolumn{3}{|c|}{ Women (number of observations $=782$ ) } \\
\hline & Odds ratio & $\begin{array}{l}95 \% \text { confidence } \\
\text { interval }\end{array}$ & $\overline{p \text {-value }}$ & Odds ratio & $\begin{array}{l}\text { 95\% confidence } \\
\text { interval }\end{array}$ & p-value \\
\hline shortTR/middleNL & 0.57 & $0.36-0.89$ & 0.013 & 0.62 & $0.40-0.97$ & 0.035 \\
\hline shortTR/longNL & Ref. & - & - & Ref. & - & - \\
\hline longTR/middleNL & 1.35 & $0.79-2.33$ & 0.274 & 0.91 & $0.49-1.71$ & 0.779 \\
\hline longTR/longNL & Ref. & - & - & Ref. & - & \\
\hline \multicolumn{7}{|l|}{ GERMANY } \\
\hline & \multicolumn{3}{|c|}{ Men (number of observations $=2383$ ) } & \multicolumn{3}{|c|}{ Women (number of observations $=2402$ ) } \\
\hline Interaction variable (length of stay in TR and DE) & Odds ratio & $\begin{array}{l}95 \% \text { confidence } \\
\text { interval }\end{array}$ & p-value & Odds ratio & $\begin{array}{l}95 \% \text { confidence } \\
\text { interval }\end{array}$ & p-value \\
\hline shortTR/shortDE & 0.22 & $0.07-0.69$ & 0.009 & 0.69 & $0.25-1.92$ & 0.478 \\
\hline shortTR/middleDE & 0.73 & $0.56-0.95$ & 0.021 & 0.81 & $0.59-1.10$ & 0.182 \\
\hline shortTR/longDE & Ref. & - & - & Ref. & - & \\
\hline longTR/shortDE & 1.38 & $0.88-2.18$ & 0.165 & 1.22 & $0.72-2.10$ & 0.456 \\
\hline longTR/middleDE & 1.44 & $1.03-2.02$ & 0.033 & 1.19 & $0.82-1.74$ & 0.358 \\
\hline longTR/longDE & Ref. & - & - & Ref. & - & \\
\hline
\end{tabular}

${ }^{1}$ Short TR $=0-17$ years, long TR $=18$ years and longer, middle NL: immigration year 1980 and later, long NL: immigration year 1979 and earlier, short DE: immigration year 2000-2009, middle DE: immigration year 1980-1999, long DE: immigration year 1979 and earlier.

${ }^{2}$ All models adjusted for education, occupation, net income per month, age, survey year (only NL).

${ }^{3}$ Rows in bold print indicate a p-value $<0.05$.

process: for example, dietary habits or leisure-time activities from the culture of the country of origin may also find their way into the culture of the host country. Consequently, adapting to the culture of the host country does not necessarily mean that one has to give up the culture of the country of origin [27-30]. Such a unidimensional concept of acculturation - merely ranging from a weak to a strong adaptation towards the culture of the host country - does not satisfy the perception of acculturation as a reciprocal phenomenon.

The tobacco policies in Germany and the Netherlands might also influence smoking patterns (but our study was not designed to test this). According to the Tobacco Control Scale by Joossens \& Raw [15] for the year 2013, the Netherlands is ranked $13^{\text {th }}$ and Germany is ranked $33^{\text {rd }}$ out of 34 countries (higher positions indicate a more successful tobacco control policy). Other authors have also stated delays in acting on tobacco in Germany $[47,48]$. Assuming that these political efforts had an influence on the smoking behaviour of Turkish immigrants, we would expect the smoking prevalence to be lower among Turks in Netherlands than in Germany. As the contrary is the case, tobacco policies appear to have little influence on the smoking behaviour of Turkish immigrants - it rather seems to be the collective, everyday life between the individuals that influences and shapes their smoking behaviour.
As current smoking patterns might not only be influenced by the situation in the host country but also by that in the country of origin, the differences in smoking behaviour among Turkish immigrants depending on LOS in Turkey and LOS in the respective host country are another important finding. Only one study so far has investigated the association between smoking behaviour and LOS in Germany where trends of convergence in smoking prevalence that differed between men and women were observed: whereas the smoking prevalence among Turkish men decreased with increasing duration of stay and converged to that of German men, the prevalence among Turkish women increased and also converged to that of German women [16]. Reiss et al. [49] observed these trends of convergence by sex also among the second largest migrant group in Germany, ethnic German immigrants from the former Soviet Union. In the study presented here, the LOS in the country of origin was additionally included to quantify its influence on the smoking behaviour.

In both Germany and the Netherlands the smoking prevalence seems to increase with increasing LOS in the host country and short LOS in the country of origin and to decrease with increasing LOS in the host country and long LOS in the country of origin. On the one hand this finding might - again - indicate an adaptation towards the host country's smoking behaviour with increasing 

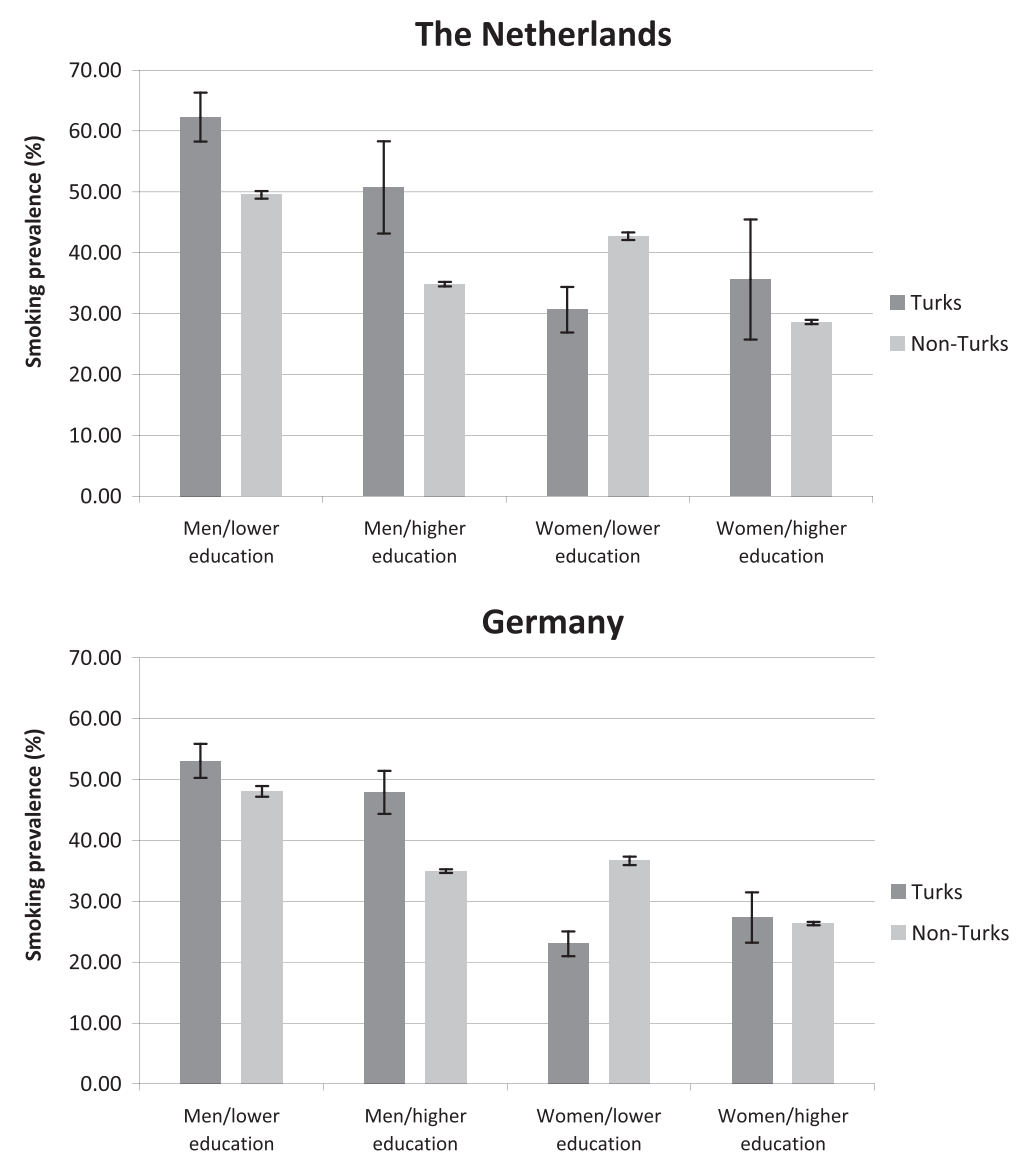

Figure 3 Comparison of age standardised smoking prevalences (in\%) between Turkish and Non-Turkish participants in the Netherlands/ Turkish and Non-Turkish participants in Germany (within-country-comparison).

LOS among those who have spent less than 18 years in Turkey. On the other hand it also reflects an 'imported' smoking pattern among those with long LOS in Turkey and short/middle LOS in the host country. Unfortunately, no clear conclusion can be drawn regarding women with long LOS in Turkey. Although reasons for these findings remain speculative, there is a clear variation in smoking behaviour depending on a temporal factor: the time spent in Turkey and the time spent in the respective host country. Therefore, there are clear indications for the importance of taking a life-course perspective on smoking behaviour. This is also suggested by Schooling \& Kuh [23]: health behaviour is subject to constant development and change during the life course; socio-economic and socio-cultural factors in childhood may, for example, influence the uptake and maintenance of certain health behaviours which can then be tracked until adulthood [50,51].

\section{Strengths and limitations}

Concerning data quality, it can be assumed that the migrant population in the micro-census is representative for the migrant population in Germany as participation in the survey is compulsory. In the Netherlands it is not obligatory to participate in the POLS. Migrants experiencing difficulties with the language of the host country are more likely to refuse study participation [52,53]. As language difficulties are often linked to a lower socioeconomic status, the Dutch data may be biased towards an overrepresentation of people with good Dutch language skills and a higher socioeconomic status. However, within this study there were only slight differences in terms of occupation, education, and income between Turks in Germany and the Netherlands (see Table 1). Still, persons of Turkish origin are not a homogeneous group. In this study no information was available for example on the region of origin, immigration reasons, religion etc. - variables which might act as confounders. While comparability of the Turkish populations living in Germany and the Netherlands may be debatable, the distributions of socioeconomic and socio-demographic variables are similar. Furthermore, we controlled for socioeconomic differences between the populations that immigrated to Germany/the Netherlands in the different migration waves. The partial inconsistency in the categorisation of smoking in Germany and the Netherlands 
is a common problem in international comparative studies. However, we do not expect substantial differences between regular and occasional smokers with respect to our study question.

The inclusion of a temporal perspective and the analysis of an association with the smoking prevalence among Turkish immigrants is a strength of this comparative study. A major limitation is that only crosssectional data was available. Hence, it was not possible to observe the smoking behaviour among the same group of Turkish migrants over several years - it is only possible to compare the smoking habits among Turkish migrants with different LOS in Turkey and in the respective host country at a certain point in time. As a result, one cannot speak of a temporal trend in the sense of a decrease or increase in smoking prevalence since it is still possible that a cohort-effect occurred: the different smoking prevalence among people with different lengths of stay might simply be the result of observing different cohorts. Thus, smoking prevalence should be studied longitudinally among the same group of people with increasing duration of stay.

Another issue is the different survey years that have been used in Germany and the Netherlands (1997-2004 vs. 2009). It might be argued that the higher smoking prevalence among Dutch participants compared to those in Germany might be attributed to a higher smoking prevalence in the past. In the Dutch data we included the survey year in all models and found no effect among Turkish men and a small effect among Turkish women in terms of a slight increase in smoking prevalence. A study from Germany has also analysed the temporal trend in smoking behaviour between 1990 and 2011. Among men a slightly decreasing trend was observed within the period of 21 years (difference between 1990 and 2011: -5.1 percentage points) and among women a slightly increasing trend was observed (difference: +2.6 percentage points). However, smoking patterns slowly decrease among women since the beginning of the new century [13]. Although a kind of temporal bias cannot be ruled out in our study, its influence is assumed to be negligible.

\section{Conclusions}

This comparative study on smoking among immigrants from the same country of origin now residing in two different host countries generated important new findings: there are indications that Turkish immigrants adapt to the different smoking behaviours of the majority population of Germany and the Netherlands. Moreover, an increasing duration of stay in the respective host country might reinforce such an adaptation process among those who left Turkey at an early age. On the other hand, the results also reflect an 'imported' smoking pattern after immigration among those who left Turkey as adults, which - again - might be prone to change with increasing duration of stay in the host countries. Public health measures have to be tailored to recent immigrants with a short duration of stay in their country of origin to prevent them from starting to smoke in the host country. Additionally, the beneficial development of a decreasing smoking pattern among recent immigrants with a long duration of stay in their countries of origin has to be supported. Due to the distinct gender differences in smoking it might also be useful to make immigrant women and men aware of the social and cultural factors that might operate during the process of immigration and afterwards. As smoking is also a strong group phenomenon, Poonia [54] advised to additionally take into account the cultural context of smoking in the countries of origin and the stressful immigration process to the host countries. Implementing measures within migrant networks and involving important community representatives might prove successful in reducing smoking prevalences among immigrants.

The new contribution of the paper is that population groups that migrated from the same country of origin and now reside in different host countries adapt to the smoking behavior of the respective host country's majority populations, even if the smoking patterns of the majority populations differ between each other. That was observed in this comparative study among immigrants from Turkey now residing in Germany and the Netherlands. Immigrants who left Turkey as adolescents are at a particularly high risk of commencing to smoke. Health care providers in the host countries should develop targeted prevention measures for this group.

\section{Endnotes}

${ }^{a}$ After 2004 no information on country of birth was available.

\section{Competing interests}

The authors declare that they have no competing interests.

\section{Authors' contributions}

OR conceived and coordinated the study. JS contributed to the acquisition of data. KR, OS and JB developed the analysis strategy. OS, JB and JS participated in the data analysis. KR performed the data analysis and drafted the manuscript. All authors made substantial contributions to the interpretation of data, read and approved the final manuscript.

\section{Acknowledgements}

The authors would like to thank the Federal Statistical Office of Germany and Statistics Netherlands for providing the data for this analysis.

Received: 7 January 2014 Accepted: 7 August 2014

Published: 14 August 2014

\section{References}

1. Doll R, Peto R, Boreham J, Sutherland I: Mortality in relation to smoking: 50 years' observations on male British doctors. BMJ 2004, 328(7455):1519-1528. 
2. Vineis $P$, Alavanja M, Buffler $P$, Fontham E, Franceschi $S$, Gao YT, Gupta PC, Hackshaw A, Matos E, Samet J, Sitas F, Smith J, Stayner L, Straif K, Thun MJ Wichmann HE, Wu AH, Zaridze D, Peto R, Doll R: Tobacco and cancer: recent epidemiological evidence. J Natl Cancer Inst 2004, 96(2):99-106.

3. Yusuf S, Hawken S, Ounpuu S, Dans T, Avezum A, Lanas F, McQueen M, Budaj A, Pais P, Varigos J, Lisheng L, INTERHEART Study Investigators: Effect of potentially modifiable risk factors associated with myocardial infarction in 52 countries (the INTERHEART study): case-control study. Lancet 2004, 364(9438):937-952.

4. Hiscock R, Bauld L, Amos A, Fidler JA, Munafò M: Socioeconomic status and smoking: a review. Ann N Y Acad Sci 2012, 1248:107-123.

5. Wilson LM, Avila Tang E, Chander G, Hutton HE, Odelola OA, Elf JL, Heckman-Stoddard BM, Bass EB, Little EA, Haberl EB, Apelberg BJ: Impact of tobacco control interventions on smoking initiation, cessation, and prevalence: a systematic review. J Environ Public Health 2012, 2012:961724

6. Federal Statistical Office of Germany: Bevölkerung und Erwerbstätigkeit. Bevölkerung mit Migrationshintergrund - Ergebnisse des Mikrozensus 2011 [Population andoccupation. People with migration background - results from the micro census 2011]. Wiesbaden, Germany: Federal Statistical Office of Germany; 2012

7. Statistics Netherlands: Bevolking: generatie, geslacht, leeftijd en herkomstgroepering. In Population: generation, sex, age and origin. http://statline.cbs.nl/StatWeb/publication/?DM=SLNL\&PA=37325\&D1=0-1\&D2= $0 \& D 3=0 \& D 4=0 \& D 5=0-2,237 \& D 6=4-17 \& H D R=G 2, G 1, G 3, T \& S T B=G 4, G 5 \& W=T$.

8. Içduygu A, Sert D: Historische Entwicklungen von Ein- und Auswanderung. In Historical development of emigration and immigration. http://www.bpb.de/ gesellschaft/migration/dossier-migration/57918/entwicklung? $\mathrm{p}=0$.

9. Butterwegge C: Von der "Gastarbeiter"-Anwerbung zum Zuwanderungsgesetz. In From the recruitment of gastarbeiter to the Immigration Law. http://www.bpb.de/gesellschaft/migration/dossiermigration/56377/migrationspolitik-in-der-brd? $\mathrm{p}=0$.

10. The Ministry of Health of Turkey: Global Adult Tobacco Survey (GATS) - Turkey Report. Ankara, Turkey: The Ministry of Health of Turkey; 2010.

11. World Health Organization: WHO report on the global tobacco epidemic. In 2013. http://www.who.int/tobacco/global_report/2013/en/

12. Nagelhout GE, De Korte-de BD, Kunst AE, van der Meer RM, De Vries $H$, Van Gelder BM, Willemsen MC: Trends in socioeconomic inequalities in smoking prevalence, consumption, initiation, and cessation between 2001 and 2008 in the Netherlands. Findings from a national population survey. BMC Public Health 2012, 12:303.

13. Lampert T, von der Lippe E, Müters S: Prevalence of smoking in the adult population of Germany: results of the German Health Interview and Examination Survey for Adults (DEGS1). Bundesgesundheitsblatt Gesundheitsforschung Gesundheitsschutz 2013, 56(5-6):802-808.

14. Willemsen M: Tobacco Control Policy in the Netherlands - A Short History. In http://stivoro.n//wp-content/uploads/2012/docs/rapporten/wetgeving/ Presentation\%20Smokefree\%20Symposium\%20100ct12\%20Marc\%20Willemsen.pdf.

15. Joossens L, Raw M: The Tobacco Control Scale 2013 in Europe. In http://www.europeancancerleagues.org/images/TobaccoControl/ TCS_2013 in Europe_13-03-14_final_1.pdf.

16. Reeske A, Spallek J, Razum O: Changes in smoking prevalence among first- and second-generation Turkish migrants in Germany - an analysis of the 2005 Microcensus. Int J Equity Health 2009, 8:26.

17. Gebhardt R, Cassens S, Liecke F, Rohde G, Gün AK, Brücker R, Pankow W: Smoke-free by ramadan: experience with a low-threshold prevention offer on smoking cessation for persons with migration background. MMW Fortschr Med 2012, 154(2):33-40.

18. Nierkens V, De Vries H, Stronks K: Smoking in immigrants: do socioeconomic gradients follow the pattern expected from the tobacco epidemic? Tob Control 2006, 15(5):385-391.

19. Acartürk CZ, Nierkens V, Agyemang C, Stronks K: Depressive symptoms and smoking among young Turkish and Moroccan ethnic minority groups in The Netherlands: a cross-sectional study. Subst Abuse Treat Prev Policy 2011, 6:5.

20. Nierkens V, Stronks K, Van Oel CJ, De Vries H: Beliefs of Turkish and Moroccan immigrants in The Netherlands about smoking cessation: implications for prevention. Health Educ Res 2005, 20(6):622-634.

21. Van Oort FV, van der Ende J, Crijnen AA, Verhulst FC, Mackenbach JP, Joung IM: Determinants of daily smoking in Turkish young adults in the Netherlands. BMC Public Health 2006, 6:294
22. Kabir Z, Clarke V, Keogan S, Currie LM, Zatonski W, Clancy L: Smoking characteristics of Polish immigrants in Dublin. BMC Public Health 2008, 8:428.

23. Schooling M, Kuh D: A life course perspective on women's health behaviours. In A life course approach to women's health. Edited by Kuh D, Hardy R. Oxford: Oxford University Press; 2002:279-303.

24. Razum O, Twardella D: Time travel with Oliver Twist - towards an explanation for a paradoxically low mortality among recent immigrants. Trop Med Int Health 2002, 7(1):4-10.

25. Berry JW: Immigration, Acculturation, and Adaptation. ApplPsychollnt Rev 1997, 46(1):5-34.

26. Rudmin FW: Catalogue of acculturation constructs: Descriptions of 126 taxonomies, 1918-2003. In Online Readings in Psychology and Culture (Unit 8, Chapter 8). Edited by Lonner WJ, Dinnel DL, Hayes SA, Sattler DN. Bellingham, Washington DC: Center for Cross-Cultural Research, Western Washington University; 2003.

27. Chakraborty BM, Chakraborty R: Concept, measurement and use of acculturation in health and disease risk studies. Coll Antropol 2010 34(4):1179-1191

28. Cabassa L: Measuring Acculturation: Where We Are and Where We Need to Go. Hispanic J Behav Sci 2003, 25(2):127-146.

29. Abraído-Lanza AF, Armbrister AN, Flórez KR, Aguirre AN: Toward a theorydriven model of acculturation in public health research. Am J Public Health 2006, 96(8):1342-1346.

30. Chun KM, Organista PB, Marin G: Acculturation: Advances in Theory, Measurement, and Applied Research. Washington DC: American Psychological Association; 2002.

31. An N, Cochran SD, Mays VM, McCarthy WJ: Influence of American acculturation on cigarette smoking behaviors among Asian American subpopulations in California. Nicotine Tob Res 2008, 10(4):579-587.

32. Bethel JW, Schenker MB: Acculturation and smoking patterns among Hispanics: a review. Am J Prev Med 2005, 29(2):143-148.

33. Choi S, Rankin S, Stewart A, Oka R: Effects of acculturation on smoking behavior in Asian Americans: a meta-analysis. J Cardiovasc Nurs 2008, 23(1):67-73.

34. Kim SS, Ziedonis D, Chen KW: Tobacco use and dependence in Asian Americans: a review of the literature. Nicotine Tob Res 2007, 9(2):169-184.

35. Marin G, Perez-Stable EJ, Marin BV: Cigarette smoking among San Francisco Hispanics: the role of acculturation and gender. Am J Public Health 1989, 79(2):196-198

36. Parker ED, Solberg LI, Foldes SS, Walker PF: A surveillance source of tobacco use differences among immigrant populations. Nicotine Tob Res 2010, 12(3):309-314

37. Pérez-Stable EJ, Ramirez A, Villareal R, Talavera GA, Trapido E, Suarez L, Marti J, McAlister A: Cigarette smoking behavior among US Latino men and women from different countries of origin. Am J Public Health 2001, 91(9):1424-1430

38. Tang H, Shimizu R, Chen MS Jr: English language proficiency and smoking prevalence among California's Asian Americans. Cancer 2005, 104(12 Suppl):2982-2988

39. Spallek J, Zeeb H, Razum O: What do we have to know from migrants' past exposures to understand their health status? A life course approach. Emerg Themes Epidemiol 2011, 8(1):6.

40. Nierkens V, van der Ploeg MV, Van Eer MY, Stronks K: How do psychosocial determinants in migrant women in the Netherlands differ from these among their counterparts in their country of origin? A cross-sectional study. BMC Public Health 2011, 11:397

41. Rechel B, Mladovsky P, Ingleby D, Mackenbach JP, McKee M: Migration and health in an increasingly diverse Europe. Lancet 2013, 381(9873):1235-1245

42. StatisticsNetherlands: Permanent OnderzoekLeefSituatie (POLS). In Integrated Survey on Household Living Conditions (POLS). [http://www.cbs.nl/ $\mathrm{nl-NL/menu/methoden/dataverzameling/permanent-onderzoek-leefsituatie-}$ pols-deelmodule-recht-en-participatie-rep2.htm]

43. The Netherlands Institute for Social Research: Permanent onderzoeknaar de leefsituatie (POLS). In Integrated Survey on Household Living Conditions (POLS). http://www.scp.nl/Onderzoek/Bronnen/Beknopte_onderzoeksbe schrijvingen/Permanent_onderzoek_naar_de_leefsituatie_POLS.

44. Federal Statistical Office of Germany: Qualitätsbericht Mikrozensus 2009 [Quality report micro census 2009]. Wiesbaden, Germany: Federal Statistical Office of Germany; 2010

45. International Agency for Research on Cancer: CANCERMondial (GLOBOCAN, Cl5, WHO). In http://www-dep.iarc.fr/ 
46. Griffiths MA, Ford EW: Hookah smoking: behaviors and beliefs among young consumers in the United States. Soc Work Public Health 2014 29(1):17-26.

47. Mackenbach JP, Karanikolos M, McKee M: The unequal health of Europeans: successes and failures of policies. Lancet 2013, 381(9872):1125-1134.

48. Grüning T, Gilmore AB, McKee M: Tobacco industry influence on science and scientists in Germany. Am J Public Health 2006, 96(1):20-32.

49. Reiss K, Spallek J, Razum O: 'Imported risk' or 'health transition'? Smoking prevalence among ethnic German immigrants from the Former Soviet Union by duration of stay in Germany - analysis of microcensus data. Int J Equity Health 2010, 9:15.

50. Twisk JWR, Kemper HCG, Van Mechelen W, Post GB: Tracking of risk factors for coronary heart disease over a 14-year period: a comparison between lifestyle and biologic risk factors with data from the Amsterdam Growth and Health Study. Am J Epidemiol 1997, 145(10):888-898.

51. Kelder SH, Perry CL, Klepp Kl, Lyte LL: Longitudinal tracking of adolescent smoking, physical activity, and food choice behaviors. Am J Public Health 1994, 84(7):1121-1126.

52. Yilmaz Y, Glodny S, Razum O: Social networking as an alternative concept for the recruitment of Turkish migrants for scientific studies. The example of the saba project. Hallesche Beiträge zur Gesundheits- und Pflegewissenschaft 2009, 8(1):636-653.

53. Schenk L: Migrant-specific participation barriers and accessiblity in The Child and Adolescent Health Survey. Gesundheitswesen 2002, 64(1):59-68.

54. Poonia J: Smoking cessation and ethnic minority communities. Findings of qualitative research project with Turkish, Polish, and Somalian communities in London. NHS Commissioning Support for London: London, England; 2009.

doi:10.1186/1471-2458-14-844

Cite this article as: Reiss et al:: How immigrants adapt their smoking behaviour: comparative analysis among Turkish immigrants in Germany and the Netherlands. BMC Public Health 2014 14:844.

\section{Submit your next manuscript to BioMed Central and take full advantage of:}

- Convenient online submission

- Thorough peer review

- No space constraints or color figure charges

- Immediate publication on acceptance

- Inclusion in PubMed, CAS, Scopus and Google Scholar

- Research which is freely available for redistribution 